\title{
Genotype-phenotype associations in PPGLs in 59 patients with variants in SDHX genes
}

\author{
Ailsa Maria Main ${ }^{1}$, Maria Rossing ${ }^{2}$, Line Borgwardt ${ }^{3}$, Birgitte Grønkær Toft ${ }^{4}$, Åse Krogh Rasmussen ${ }^{5}$ and \\ Ulla Feldt-Rasmussen (106 \\ 'Department of Medical Endocrinology and Metabolism, Copenhagen University Hospital, Rigshospitalet, Copenhagen, Denmark \\ ${ }^{2}$ Center for Genomic Medicine, Copenhagen University Hospital, Rigshospitalet, Copenhagen, Denmark \\ ${ }^{3}$ Center for Genomic Medicine, Copenhagen University Hospital, Rigshospitalet, Copenhagen, Denmark \\ ${ }^{4}$ Department of Pathology, Copenhagen University Hospital, Rigshospitalet, Copenhagen, Denmark \\ ${ }^{5}$ Department of Medical Endocrinology and Metabolism, Copenhagen University Hospital, Rigshospitalet, Copenhagen, Denmark \\ ${ }^{6}$ Department of Medical Endocrinology and Metabolism, Copenhagen University Hospital, Rigshospitalet, and Faculty of Health, Institute of Clinical and \\ Scientific Research, Copenhagen, Denmark
}

Correspondence should be addressed to A M Main or U Feldt-Rasmussen: ailsa.maria.main.02@regionh.dk or ufeldt@rh.dk

\begin{abstract}
Phaeochromocytomas and paragangliomas (PPGLs) are tumours of the adrenal medulla and extra-adrenal sympathetic nervous system which often secrete catecholamines. Variants of the SDHX (SDHA, $-A F 2,-B,-C,-D)$ genes are a frequent cause of familial PPGLs. In this study from a single tertiary centre, we aimed to characterise the genotype-phenotype associations in patients diagnosed with germline variants in SDHX genes. We also assessed whether systematic screening of family members resulted in earlier detection of tumours. The study cohort comprised all individuals $(n=59)$ diagnosed with a rare variant in SDHX during a 13-year period. Patient- and pathology records were checked for clinical characteristics and histopathological findings. We found distinct differences in the clinical and histopathological characteristics between genetic variants in SDHB. We identified two $S D H B$ variants with distinct phenotypical patterns. Family screening for $S D H B$ variants resulted in earlier detection of tumours in two families. Patients with SDHA, $S D H C$ and $S D H D$ variants also had malignant phenotypes, underlining the necessity for a broad genetic screening of the proband. Our study corroborates previous findings of poor prognostic markers and found that the genetic variants and clinical phenotype are linked and, therefore, useful in the decision of clinical follow-up. Regular tumour screening of carriers of pathogenic variants may lead to an earlier diagnosis and expected better prognosis. The development of a combined algorithm with clinical, genetic, morphological, and biochemical factors may be the future for improved clinical risk stratification, forming a basis for larger multi-centre follow up studies.
\end{abstract}

\section{Key Words}

- genotype

- phenotype

- PPGL

\section{Introduction}

Phaeochromocytomas and paragangliomas (PPGLs: PCCs (MIM: 171300), PGL1 (MIM: 168000), PGL2 (MIM: 601650), PGL3 (MIM: 605373), PGL4 (MIM: 115310), PGL5 (MIM: 614165), PGL6 (MIM: 618464)) are tumours of the adrenal medulla and extra-adrenal sympathetic nervous system, respectively, that often secrete catecholamines. Paragangliomas (PGLs) arising from the parasympathetic nervous system are often non-secreting tumours located in the head and neck region (termed head and neck paragangliomas (HNPGLs)) (1). Because of the strong heritability, genetic testing is recommended in all patients with PPGLs and, when a variant is detected, also screening of their family members $(1,2,3,4,5)$. Markers of poor prognosis in PPGLs have been identified in 
different studies, including tumour size $>5 \mathrm{~cm}$, vascular invasion, SDHB variants and norepinephrine secretion (6). There is, however, little information about the clinical phenotype associated with the individual genetic variants $(6,7)$.

PPGLs are very heterogeneous tumours and more than 20 predisposing genes have been identified (6). In two-thirds of the PPGL patients, a pathogenic germline or somatic variant can be found and PPGLs have been divided into distinct biological subgroups (kinase signaling, pseudohypoxia and Wnt signaling) on the basis of these variants (6). Most PPGLs are non-metastatic tumours but approximately $15 \%$ are malignant (6). Malignancy status is given to metastatic disease at distant sites unrelated to the paraganglia tissues (6). The overall 5-year survival for malignant PPGLs is approximately $60 \%$ (8). Germline variants in succinate dehydrogenase $(S D H)-A,-A F 2,-B,-C$, and -D (MIM: 600857; MIM: 613019; MIM: 185470; MIM: 602413; MIM: 602690) have been found to account for approximately half of the hereditary PPGLs (9) and for up to $15 \%$ of all patients with PPGLs (10).

The SDHX genes belonging to the SDH gene family encode a protein complex, which is involved in the Krebs cycle and the respiratory chain and are classified as tumour suppressors $(9,10,11,12)$. A germline variant of $S D H B$ is the best-known genetic predictor of malignancy as approximately $50 \%$ of tumours progress to metastatic disease $(6,13)$. Two-thirds of malignant PPGLs, however, do not harbour $S D H B$ variants (6) and other predictive markers of poor prognosis have been investigated. The PASS (phaeochromocytoma (PCC) of the adrenal gland scaled score) was developed to identify those PCCs (not PGLs) that have metastatic potential based on a score $\geq 4$ (14). The PASS method has a number of limitations in the clinical setting as the inter- and intra-observer variability is high $(6,15,16)$. A recent study found that the PASS was best used clinically to rule out, rather than rule in, malignancy potential for PPGLs due to low positive predictive value and relatively higher negative predictive value (17).

Thus, existing prognostic markers cannot fully predict PPGL behaviour $(6,18)$, which is a clinical challenge. To our knowledge, there is no previous systematic study of the genotype-phenotype associations in patients with solely germline variants in SDHX genes. In this study, we aim to characterise the possible associations between genotype on the one hand and the clinical and histopathological presentation on the other in 59 individuals diagnosed with germline variants in $S D H X$ genes in the setting of a single tertiary referral centre.

\section{Methods}

\section{Study cohort}

The study cohort comprised all individuals diagnosed with a variant of one of the $S D H X$ genes between 1 January 2006 and 1 March 2019 who were followed in the Department of Medical Endocrinology, Copenhagen University Hospital, Rigshospitalet. All individuals with a proven variant in the $S D H X$ genes (class 3, 4, or 5) were included. The persons were identified by their social security number in the Danish National Patient Registry. Genetic screening, variant classification, and clinical workup were carried out at the Centre for Genomic Medicine, Copenhagen University Hospital, Rigshospitalet. The study was approved by the Data Protection Agency (I-Suite number 6712) and the National Committee on Health Research Ethics, Denmark (H-1803546). The approval included a dispensation for collecting an informed consent and the study was performed according to the flow chart in Fig. 1.

\section{Genetic test results}

The screening was part of the family counselling of PPGL patients and their relatives (pre-symptomatic screening). The genetic screening methods have previously been described in detail (11). In brief, genomic DNA was isolated from whole blood using a QIAmp DNA mini kit (Qiagen) according to the instructions provided by the manufacturer. From 2006 to 2014, SDHX genes were amplified by PCR followed by Sanger sequencing using an ABI3730 DNA analyser (Applied Biosystems). Genomic DNA was examined for large genomic rearrangements by Multiplex ligation-dependent probe amplification (MLPA) using SALSA ${ }^{\circledR}$ MLPA® Probemix P226-D1 SDH. Since 2014 the analysis has been done by next-generation sequencing (NGS) on a MiSeq (Illumina, San Diego, USA). The sequencing data were analysed using SequencePlot (JSI Medical Systems, Germany) where variants were called if the allele frequency was above $25 \%$. The following genes were included in the genetic screening: $S D H A$, SDHAF2, SDHB, SDHC, and SDHD. Variants were classified according to American College of Medical Genetics (ACMG) guidelines (19). Only class 3, 4, and 5 variants were included in the diagnostic report.

\section{Clinical records}

Patient records were obtained from electronic patient records (Epic) or local archives. Clinical characteristics,

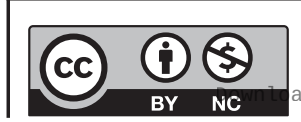

This work is licensed under a Creative Commons Attribution-NonCommercial 4.0 International License. ded from Bioscientifica.com at 04/26/2023 10:19:28AM 


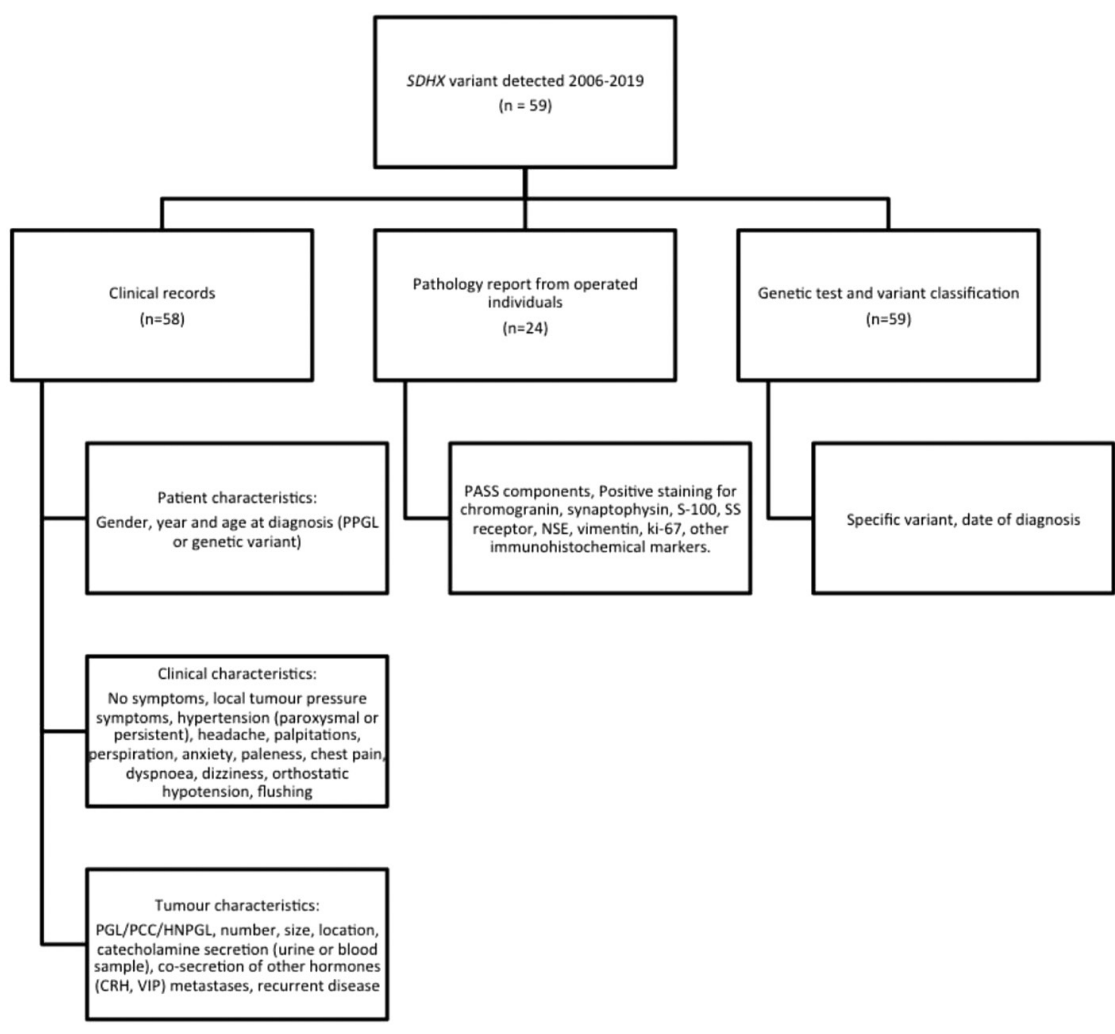

Figure 1

Flow chart of the study. CRH, corticotropinreleasing hormone; HNPGL, head and neck paraganglioma; ki-67, antigen associated with cellular proliferation; NSE, neuron-specific enolase; PASS, phaeochromocytoma of the adrenal gland scaled score; PCC, phaeochromocytoma; PGL, paraganglioma; PPGL, phaeochromocytoma and paraganglioma; SDHX, succinate dehydrogenase genetic variants; SS receptor, somatostatin receptor; VIP, vasoactive intestinal peptide. biochemistry, and imaging results at the time of PPGL diagnosis were extracted and validated by a second observer (senior clinician). One patient had previously been described (20).

\section{Pathology reports}

The pathology reports were retrieved from the national database (PatoBank) or from local archives for all patients who had undergone surgery for PPGLs. Subsequently, the reports were studied for specific histopathological findings. Malignancy of PPGLs was defined as proof of metastases based on the European Society of Endocrinology guidelines (3). Together with the genotype, Ki-67\% labelling index, secretion of hormones, tumour size and location, and clinical symptoms, we included components of the PASS score to cover all possible markers of poor prognosis reported in the literature (6).

\section{Statistical analysis}

The difference between the age of disease onset in men and women was tested with the Mann-Whitney's $U$-test and the difference between the number of men and women in the cohort by the Chi-squared test.
All other results are descriptive. Due to low numbers in the subgroups, we neither performed statistical analysis nor power calculations for these results.

All SDHX variant positive patients were grouped according to their respective variants. Thus, a group of two $S D H A$ variant positive patients, a group of $S D H B$ variant positive patients (eight families (Family B1-B8) and four unrelated patients $(\mathrm{Bx})$ ), four patients with $S D H C$ variants (two unrelated patients and two patients from the same family), and two unrelated patients with SDHD variants were identified. For $S D H A, S D H B, S D H C$, and $S D H D$ variants, the letters ' $\mathrm{A}$ ', ' $\mathrm{B}$ ', ' $\mathrm{C}$ ', or ' $\mathrm{D}$ ' were included in the patient identification (ID). To ensure patient anonymity, each patient within an SDHX positive family was given an arbitrary number and either the letter ' $\mathrm{F}$ ' (female) or 'M' (male).

Families B1-B8 were compared by the age of onset, tumour characteristics, clinical symptoms, histopathological findings, and signs of malignant disease for the patients with PPGLs. The unrelated SDHB (Bx) group was compared to other $S D H B$ families or family members with variants in the same exon(s) when possible. The patients who developed tumours and had class 4 and 5 genetic variants were compared by the age of onset and malignancy. 
For all individuals who had not yet developed PPGLs, the total number of years without disease were calculated from the date of genetic diagnosis until 1 March 2019.

\section{Results}

The characteristics of the cohort are shown in Table 1.

In total, 59 individuals were diagnosed with an $S D H X$ variant during a 13-year period. We were able to retrieve clinical records for 58 of these. One medical file was lost and for this patient we were only able to retrieve the pathology report and genetic test. A total of 24 SDHX variant positive patients underwent surgery (Fig. 1).

The median age at PPGL diagnosis was 42.5 years. There was no sex difference between the median age at tumour diagnosis of women $(40.5$ years $(n=14))$ compared to men $(45.5$ years $(n=10),(P=0.62))$ or for the number of individuals with an SDHX variant (30 female, 29 male, $P=0.34$ ) (Table 1).

Most patients were diagnosed with variants in the $S D H B$ gene (51/59). Only two, four, and two individuals were positive for variants in $S D H A, S D H C$, and $S D H D$, respectively, while no patients were positive for SDHAF2. A total of 18 PPGLs and 5 PCCs were diagnosed. Proof of metastases was found in 12 out of 59 patients. Seventeen out of $51 S D H B$ variant patients were diagnosed with PPGLs. One of the SDHA variant positive patients $(n=2)$ was diagnosed with a PGL. All SDHC $(n=4)$ and one SDHD patient developed PPGLs. Three patients were diagnosed with renal cell carcinoma, two with an SDHB variant and one with a variant of the SDHD gene (Table 1 ).
The histopathological characteristics of the tumours are shown in Supplementary material (see section on supplementary materials given at the end of this article).

In total, the cohort had 12 probands and 41 family members with a class 4 or 5 variant and 6 individuals with a class 3 variant. Among the 41 family members, two individuals were diagnosed with tumours at the first screening and two with tumours during routine screenings after 2 and 7 years. Three family members with a class 4 or 5 variant that had been treated for tumours earlier in life and were diagnosed with the genetic variant many years later during family screening. Thirty-four family members with a class 4 or 5 variant have been followed for an average time of 48.8 months (range: 11 days to 136 months) without tumour detection.

Comparison of patients with class 4 and 5 variants ( $n=19 ; 1 S D H A, 15 S D H B$ and 3 SDHC) showed that 10 of 19 developed metastatic disease and that the age at tumour diagnosis was related to the genotype with family B1 presenting with tumours at a lower age than family B3 (Fig. 2). The patients with class 4 and 5 variants in $S D H B$ presented mostly with PGLs; only one patient had both a PCC and a PGL. Three SDHB patients had nonmetastatic PGLs and both cases with renal cell carcinomas were confined to the kidney. Within the $S D H B$ variant group, two genetic variants showed a specific age distribution of first tumour diagnosis. In family B1, PGLs were detected between the age of 12 and 28 years and $75 \%$ were with metastatic disease. In family B3, metastatic or non-metastatic PGLs or renal cell carcinomas confined to the kidney were diagnosed between the age of 28 and 57 years. Family B4 had the same variant as family B3 and the

Table 1 Characteristics of SDHX variant positive patients.

\begin{tabular}{lcc}
\hline Characteristics & & Total $(n)$ \\
\hline Females, $n$ & 30 \\
Males, $n$ & & 29 \\
Total, $n$ & 59 \\
\hline Genetic variants & SDHA \\
\hline Total $(n)$ & 2 \\
Patients with PPGL diagnosis, $n$ & 1 \\
PGL, $n$ & 1 \\
PCC, $n$ & 0 \\
RCC, $n$ & 0 \\
Patients, $n$ & 1 \\
Clinical symptoms reported at PPGL diagnosis, $n$ & 0 \\
\hline
\end{tabular}

\begin{tabular}{c}
\hline With PPGL \\
\hline 14 \\
10 \\
24 \\
\hline SDHB \\
\hline 51 \\
17 \\
13 \\
4 \\
2 \\
7 \\
8 \\
\hline
\end{tabular}

\begin{tabular}{c} 
No PPGL \\
\hline 16 \\
19 \\
35
\end{tabular}

\begin{tabular}{c}
\hline SDHC \\
\hline 4 \\
4 \\
4 \\
0 \\
0 \\
2 \\
3 \\
\hline
\end{tabular}

\begin{tabular}{c}
\hline Age (years) at first PPGL diagnosis range (median) \\
\hline $17-65(40.5)$ \\
$12-73(46.5)$ \\
$12-73(42.5)$ \\
\hline SDHD \\
\hline 2 \\
1 \\
0 \\
1 \\
1 \\
2 \\
0
\end{tabular}

A patient may display both a phaeochromocytoma and a paraganglioma or a renal cell carcinoma (RCC), therefore the total $n$ is larger than total number of patients with PPGLS.

PCC, phaeochromocytoma; PGL, paraganglioma; PPGL, phaeochromocytoma and paraganglioma; SDHX, succinate dehydrogenase genetic variants.

https://ec.bioscientifica.com https://doi.org/10.1530/EC- (c) 2020 The authors Published by Bioscientifica Ltd

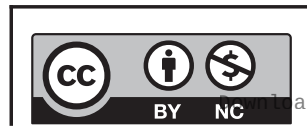

This work is licensed under a Creative Commons Attribution-NonCommercial 4.0 International License. ded from Bioscientifica.com at 04/26/2023 10:19:28AM via free access 


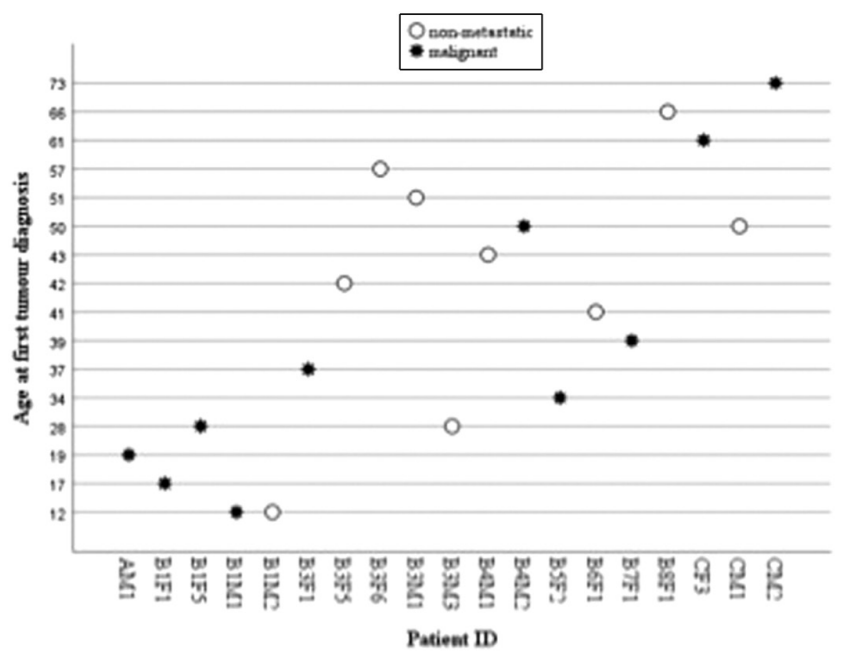

\section{Figure 2}

Age at first tumour diagnosis (PPGL or RCC) in patients with class 4 and 5 variants of SDHA $(n=1)$, SDHB $(n=15)$, and SDHC $(n=3)$ genes (open circles depict non-metastatic tumours, stars show metastatic disease). None of the SDHD variants were class 4 or 5. AM1, SDHA family, male 1; B1F1 to B8F1, SDHB families 1, 3, 4-8; F, female; M, male; CF3 to CM2, SDHC families; RCC, renal call carcinoma; PPGL, phaeochromocytoma and paraganglioma; $\mathrm{SDH}$, succinate dehydrogenase.

patients were diagnosed with either renal cell carcinoma confined to the kidney or metastatic PGL at the age of 43 and 50 years.

All patients with SDHC variants were diagnosed after the age of 50 years. Two patients with metastatic disease were unrelated and older than the patient with the non-metastatic tumour (Fig. 2). In total, six variants were classified as class 3 (three $S D H B$, one $S D H C$, and two $S D H D)$.

\section{SDHB positive patients and carriers}

Patient with variants in $S D H B$ came from eight families and four were unrelated (Supplementary material). A complete histopathological characterisation is found in Supplementary material and the different genetic variants and corresponding clinical outcome are shown in Table 2 .

In family B1 (class 5 , deletion of exon 4 and 5 in $S D H B)$, four members developed PPGLs. The tumours had different markers of poor prognosis, including metastatic disease, nuclear pleomorphism, capsular invasion, mitotic figures $>3 / 10 \mathrm{HPF}$, extension into adipose tissue and $\mathrm{Ki}-67 \%$ of $15 \%$ in one case (Supplementary material). The tumours developed early in life (12-28 years). F1 and M1 were genetically diagnosed after the onset of disease, but in two family members (F4 and F5) tumours were detected during screening after 2 and 7 years of follow-up. Neither has yet had a recurrence. The family members who were not screened prior to PPGL diagnosis had larger tumours, which secreted catecholamines, gave rise to clinical symptoms, recurrent disease, and metastases (Supplementary material and Table 3).

The homozygous proband (child of consanguineous parents) in family B2 (class 5 variant in exon 8, c.769C $>\mathrm{G}$, p.Leu257Val) died at the age of 25 months from a severe respiratory infection with multi-organ failure. All heterozygous members $(2 \mathrm{~F}, 4 \mathrm{M})$ were tumour-free.

In family B3 (class 4 variant in exon 1, c.3G>A, p.Met1?), five members were diagnosed with PPGLs (3 F, $2 \mathrm{M}$ ) between 28 and 57 years of age. One female (F6) and one male (M1) were diagnosed with a tumour at the first screening. The family members with PPGLs displayed markers of poor prognosis including metastatic disease and markers included in the PASS (Supplementary material) and the variant might be associated with a high risk of tumour development in adults (five out of nine family members) (Table 2). Family B4 carried the same variant as family B3 and two family members were diagnosed with tumours (M1, M2) (Supplementary material) and the PGL was disseminated at diagnosis.

One female in family B7 (class 5 variant in exon 7, c. $653 \mathrm{G}>\mathrm{A}$, p.Trp218*) was diagnosed at the age of 39 years, the other carrier (M1) has until now (84 years) not been diagnosed with PPGLs. The primary tumour found in $\mathrm{F} .1$ had a $\mathrm{Ki}-67 \%$ of more than $1 \%(50 \%)$ and poor prognostic histopathological markers, including necrosis, mitotic figures $>3 / 10 \mathrm{HPF}$, vascular invasion, and nuclear pleomorphism. Later, F.1 had a new event with metastases (Supplementary material). In family B5, the tumour metastases also had a higher Ki-67\% >1 (Supplementary material).

The proband (F1) of family B8 was diagnosed with a class 5 variant (c.683_684del, p.Glu228Glyfs*27) in exon 7. This tumour was smaller and had a lower Ki-67\% index than the primary tumour in family B7 and no recurrence of disease (Supplementary material).

Two of four unrelated patients (Bx, $4 \mathrm{~F}$ ) were diagnosed with PPGLs. F2 and F5 both had class 3 variants (Table 2) and developed PCCs with clinical symptoms (Table 3).

In total, seven patients with class 4 and 5 SDHB variants developed metastatic disease, the highest number being found in family 1 (Table 2). None of the patients with the class 3 SDHB variants developed metastatic disease.

Tumour types and clinical symptoms of hormone secretion in patients with an $S D H B$ variant are depicted in Table 3. The predominant tumour type was PGL with symptoms of catecholamine excess and local tumour pressure.

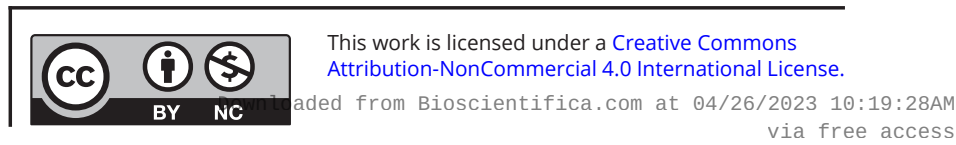




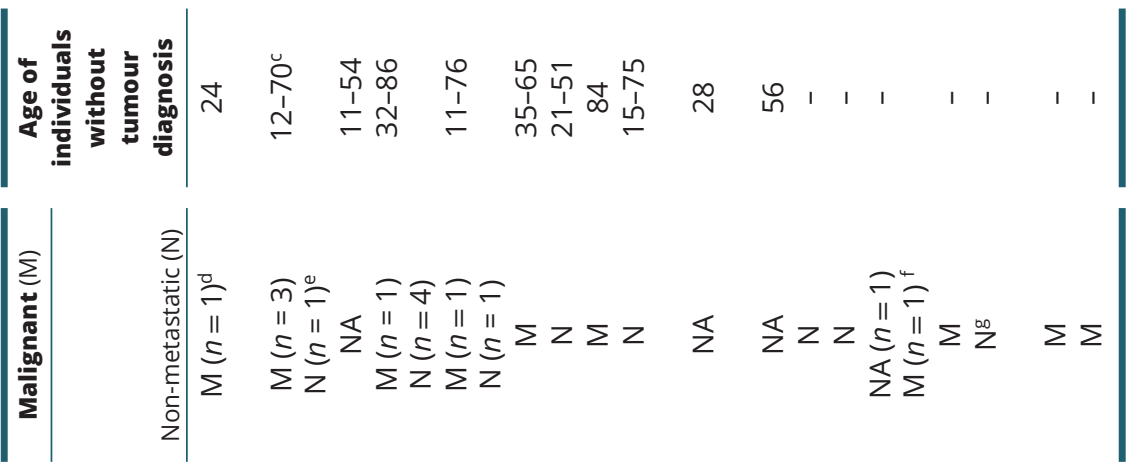

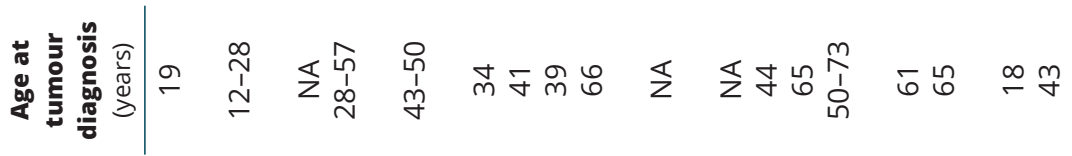

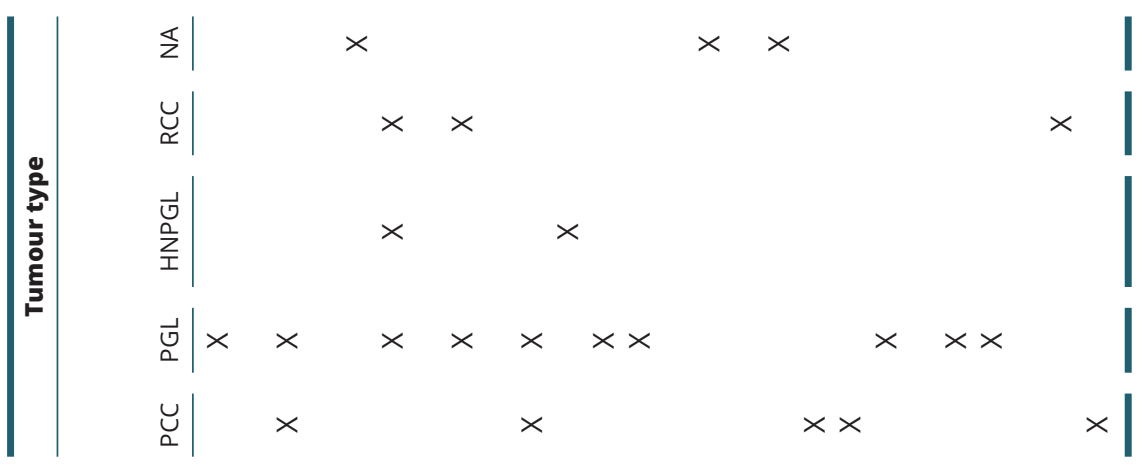

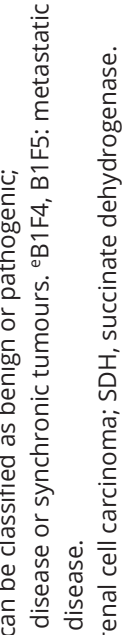

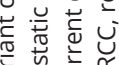

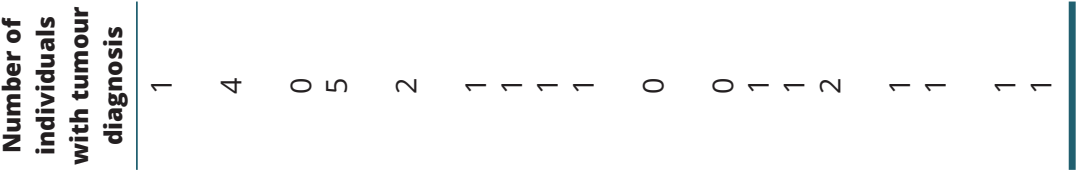

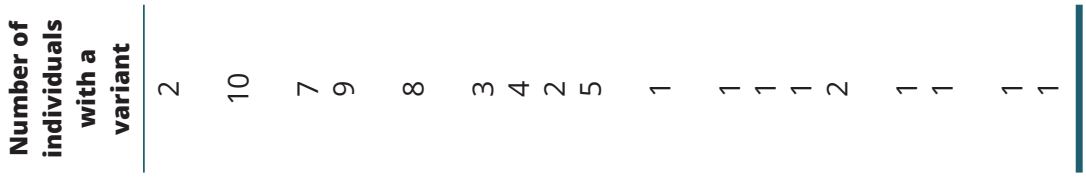

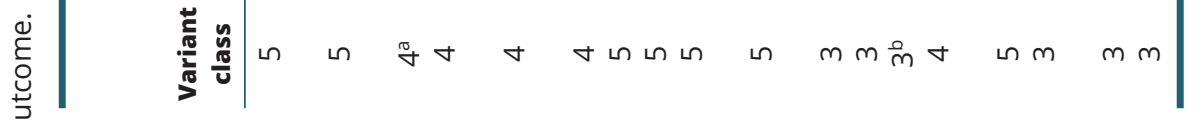

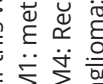
$\frac{\sum^{\prime}}{\sum_{0}}$

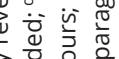

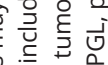
品

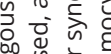

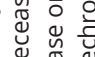
离 称

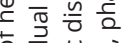

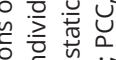
垔

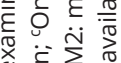
年

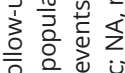
눈 

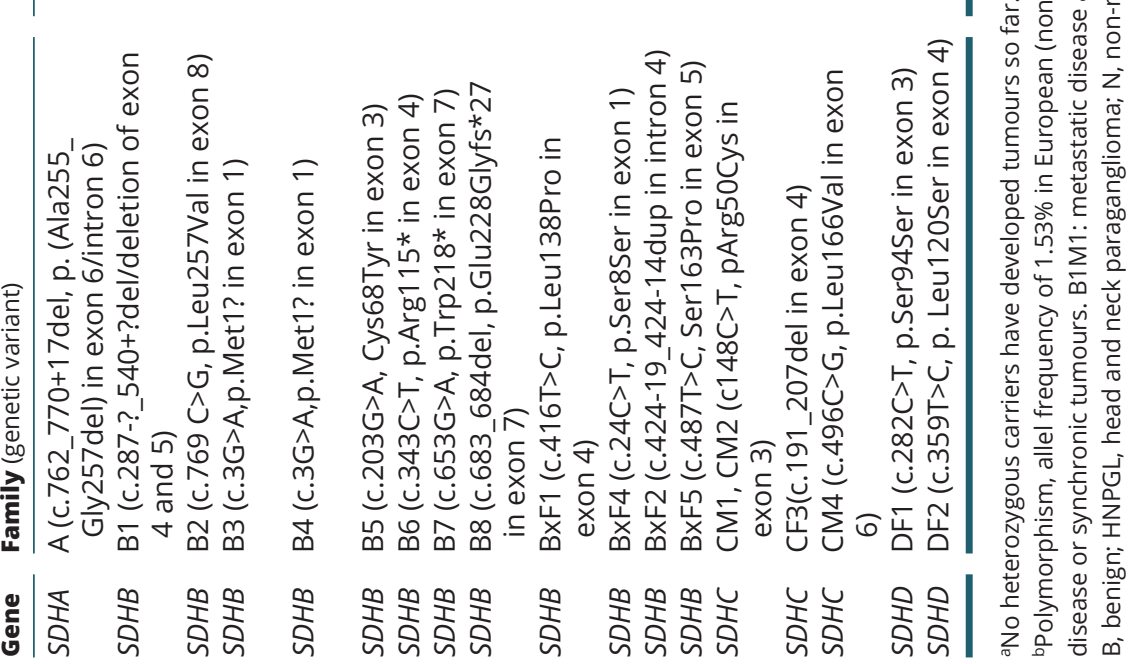



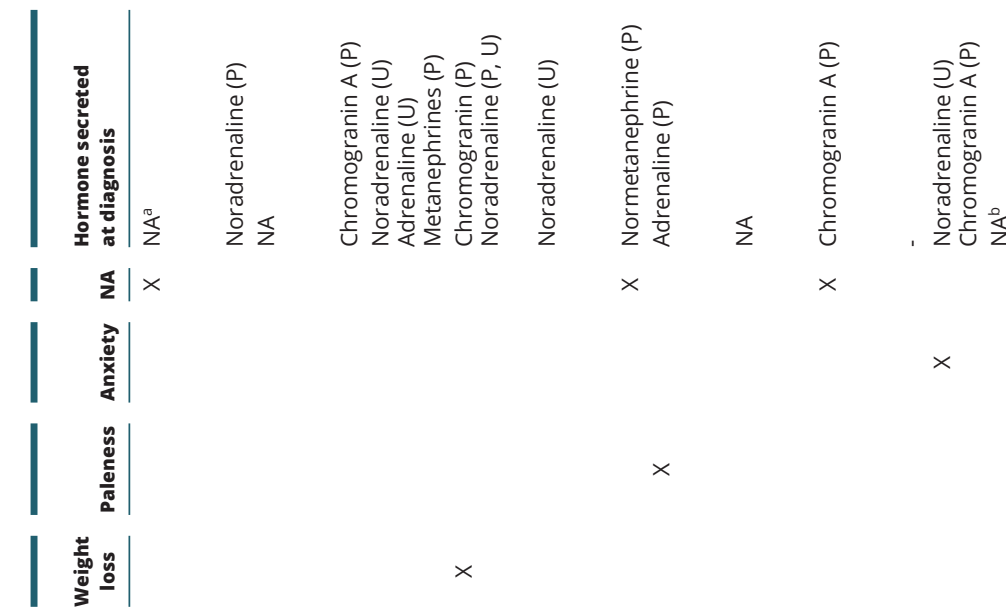

产

产
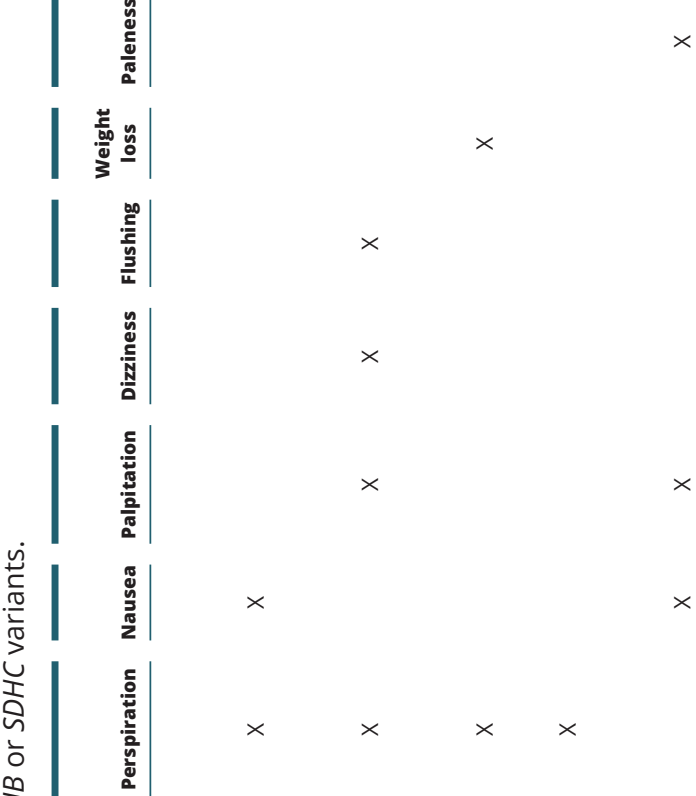

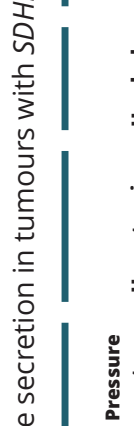
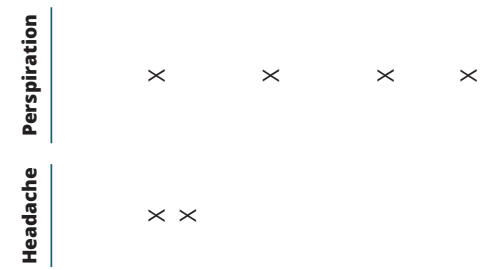

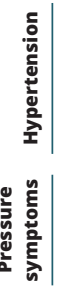

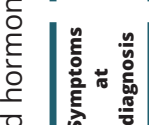

है।

$\mid$

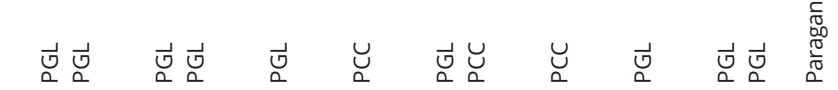

离

$\frac{\sqrt{5}}{\frac{3}{2}}$

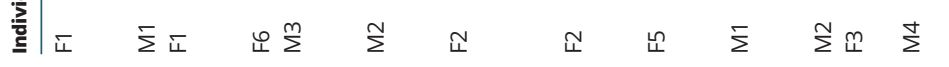

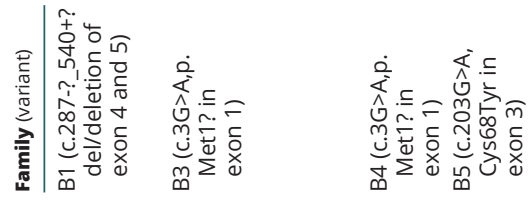

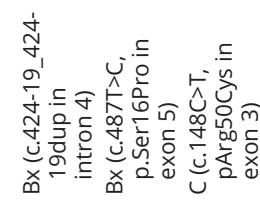
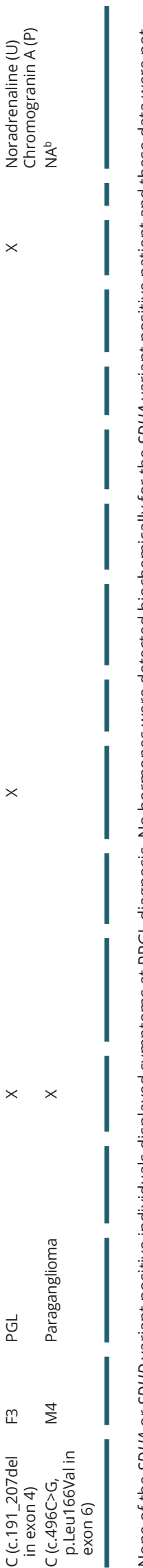

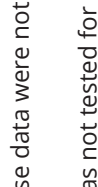

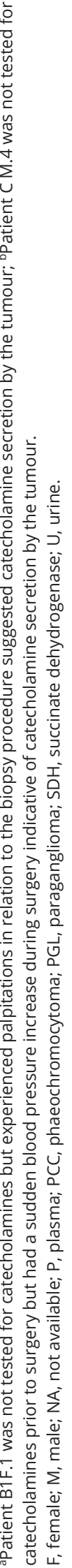




\section{SDHA, SDHC and SDHD positive patients and carriers}

A 19-year-old male with an SDHA variant (deletion in exon 6/intron 6) had two metastatic PPGLs which could also be interpreted as synchronous tumour events. There was one carrier in the family (female) who was healthy at the age of 24 years (Supplementary material).

All patients with an SDHC variant ( 1 F, $3 \mathrm{M}$ ) developed PGLs, hereof two with metastatic disease. One of these was detected in a patient carrying a class 3 variant (Table 2). All available SDHC histopathology records described tumour necrosis (Supplementary material). The predominant symptom at diagnosis was pressure symptoms, and the tumours secreted both chromogranin A and catecholamines (Table 3).

Two women were diagnosed with two class 3 variants in the SDHD gene, exon 3 and 4, respectively (Supplementary material). DF1 was diagnosed with a malignant renal carcinoma and DF2 with a metastatic PCC.

\section{Discussion}

To our knowledge, this is the first systematic study of a single tertiary centre cohort of 59 individuals with germline SDHX variants describing the associations between the genotype on the one hand and both the clinical and histopathological phenotype on the other. $S D H B$ variants were the most frequent, which is in accordance with previous reports $(9,10,12,18,21)$. Two patients were diagnosed with a variant in $S D H A$ and four patients were diagnosed with $S D H C$ variants, which corroborates previous findings that these are much less common $(9,10,12,22)$. Only two individuals were diagnosed with $S D H D$ variants, although these have been described as more common in other populations $(9,10,12)$.

Our patient cohort of $S D H X$ variant positive individuals consisted of almost equal numbers of females (30/59) and males (29/59) which was expected from the autosomal dominant heritance with incomplete penetrance of $S D H A,-B,-C,-D$ or $-A F 2$ variants located at chromosomes $5,1,1,11$, and 11 , respectively. There was also no significant sex difference in whether or not the patient developed tumours. The SDHA positive family $(n=2)$ has, to our knowledge, a novel class 4 variant not previously reported. This variant was associated with PGLs already at the age of 19 years, thus underlining the necessity for continuous screening. $S D H B$ variants are common and have a high penetrance compared to other SDHX variants resulting in development of abdominal PGLs, HNPGLs, and SDH deficient renal carcinomas $(10,12,22)$. The class 4 and 5 variants in our cohort predisposed to metastatic or non-metastatic PGLs and renal cell carcinomas without local invasion or metastases which correlated with previous findings $(9,10,12)$. In family B2, no heterozygous individual with a class 5 missense variant (c.769C>G, p.Leu257Val) in exon 8 of the $S D H B$ gene has as yet developed PPGLs. Literature, however, suggests an increased risk (20), indicating a low penetrance for this specific variant. The homozygous proband's clinical course supports the international recommendation that sequencing of $S D H B,-D$, and possibly $-C$ should be performed in patients suspected for or diagnosed with multisystem mitochondrial disorder and complex II deficiency (20).

The patients and healthy family members were included in a follow-up programme according to available international guidelines, from the year 2016 those of European Society of Endocrinology (3) with genetic testing and regular tumour screening (plasma or urinary catecholamines and chromogranin A every year, imaging every 1-2 years). This revealed tumour development before the onset of symptoms at younger ages than the proband (family B1). Tumours were consequently smaller at diagnosis and more often non-metastatic (family B1). Furthermore, one female and one male were diagnosed with PGL at the very first screening (family B3).

Distinct differences were found in the clinical picture and histopathology between various genetic variants which in the future may prove useful for the development of more individualised clinical guidelines for follow-up. Notably, families B1 and B3 showed distinct differences in age of first tumour diagnosis. Families B3 and B4 carry the same start loss variant (class 4 variant in exon 1 of $S D H B$, c.3G $>$ A, p.Met?) that is likely pathogenic (11) and both families had clinical signs of poor prognosis. Families B5 and B7 support the hypothesis that a Ki-67 index $>1 \%$ is a possible marker for malignancy in PPGLs $(6,23)$.

Variants in the SHDC gene usually predispose to nonmetastatic and multiple HNPGLs $(9,10,12)$. All four of our SDHC variant individuals developed tumours (HNPGLs and PPGLs), two with proof of metastasis and two showed catecholamine-related symptoms, which, according to the literature, are two very rare findings (9). One of the individuals with proof of metastasis had a class 3 variant further underlining that the tumour classification alone cannot predict clinical the phenotype (24). Larger studies of the genotype-phenotype associations are needed to 
elucidate how the different genetic variants in PPGLs may be stratified into prognostic risk categories. Furthermore, a study suggested that the variant type (truncating vs missense) in SDHD had an important clinical impact (25).

Variants in the SDHD gene usually predispose to multiple HNPGLs and less often PPGLs (10). However, in our cohort, the SDHD positive individuals developed malignant renal cell carcinoma and metastatic phaeochromocytoma. According to the literature, only one previous case of renal cell carcinoma has been reported in a patient with an $S D H D$ variant (26).

Our study was based on the Danish National Patient Registry, which ensures that patient records are easily found. In fact, only one clinical record was missing and we obtained both genetic test results and pathology reports from all relevant individuals. The registry has previously been validated as a valuable tool for research in rare diseases (27). Our study included all patients diagnosed since 1 January 2006 in the Department of Endocrinology, Copenhagen University Hospital, Rigshospitalet, resulting in 59 patients. A national cohort would increase the power to detect differences between specific genotypes and corresponding phenotypes and possible regional differences. It has previously been shown that the distribution of RET variants in Denmark differs from other populations, possibly due to a founder effect (28), and that the same could be the case for SDHX variants, as other countries have shown differences in clinical presentation of $S D H X$ mutations (29).

The clinical records obtained did not always include a description of subjective symptoms. This is a well-known drawback of retrospective studies and a potential source of recall bias or bias due to clinical practice, that is, whether the individual was asked about subjective symptoms or not. Some of the individuals have only recently been diagnosed with a familial genetic variant in $S D H X$ and may not yet have developed tumours because of the short follow-up time or young age. The pathology reports obtained for this study were carried out by different pathologists and, therefore, the interpretation of the findings may be subject to observer variation.

We decided to define malignancy for PPGLs as proof of metastases based on the guidelines $(3,30)$. Together with the genotype, Ki-67\% labelling index, secretion of hormones, tumour size, location, and clinical symptoms, we included components of the PASS score to cover all possible markers of poor prognosis reported in the literature (6). The PASS was not originally developed for PGLs and, therefore, there is some uncertainty in applying the components of the PASS to these tumours. The clinical features and histopathological characteristics are, however, similar for PCCs and PGLs (31).

In summary, our study corroborates previous findings of poor prognostic markers $(6,12)$. Furthermore, we found that the genetic variants are linked to the clinical and histopathological phenotype and prognosis and therefore useful for the decision of clinical follow-up. Family screening for $S D H B$ variants allowed an earlier detection of smaller tumours with better prognosis in one family (B1) and detection of tumours at the first screening in another (B3). This supports current guidelines recommending family screening. Within our cohort, two $S D H B$ variants (a deletion of exon 4 and 5 and c.3G $>$ A, p.Met1? in exon1) were identified in individuals with specific phenotypes which may be relevant in future counselling. The SDHA, SDHC and SDHD patients in our cohort included malignant phenotypes, underlining the necessity to screen for all SDHX variants and, if positive, we recommend family screening to improve early tumour detection and thereby better prognosis. The development of an objective combined algorithm with clinical, genetic, morphological, and biochemical factors may be the future for clinical individualized risk stratification.

\section{Supplementary materials}

This is linked to the online version of the paper at https://doi.org/10.1530/ EC-20-0279.

\section{Declaration of interest}

The authors declare that there is no conflict of interest that could be perceived as prejudicing the impartiality of the research reported.

\section{Funding}

Ulla Feldt-Rasmussen's research salary was supported by an unrestricted research grant from the Novo Nordisk Foundation.

\section{Author contribution statement}

Ulla Feldt-Rasmussen was the supervisor and performed project planning, data analysis and interpretation. Ailsa Maria Main performed data collection, data analysis, statistics, interpretation, and article writing. Åse Krogh Rasmussen was the co-supervisor and performed project planning, data analysis and interpretation. Caroline Maria Rossing performed collection of existing genetic results from database, genetic reruns by NGS, interpretation of genetic results, and provided expert counselling on clinical genetics and formulated the section on genetics under 'methods'. Line Gutte Borgwardt performed collection of existing genetic results from database, genetic reruns by NGS and interpretation of genetic results. Birgitte Grønkær Toft provided expert counselling on pathology reports. 


\section{Acknowledgements}

The authors thank all participating patients and their families. The authors also wish to acknowledge the technicians for their skilled labour.

\section{References}

1 Toledo RA, Burnichon N, Cascon A, Benn DE, Bayley JP, Welander J, Tops CM, Firth H, Dwight T, Ercolino T, et al. Consensus statement on next-generation-sequencing-based diagnostic testing of hereditary phaeochromocytomas and paragangliomas. Nature Reviews Endocrinology 201713 233-247. (https://doi.org/10.1038/ nrendo.2016.185)

2 Andersen GS, Toftdahl DB, Lund JO, Strandgaard S \& Nielsen PE. The incidence rate of phaeochromocytoma and Conn's syndrome in Denmark, 1977-1981. Journal of Human Hypertension 19882 187-189.

3 Plouin PF, Amar L, Dekkers OM, Fassnacht M, Gimenez-Roqueplo AP, Lenders JW, Lussey-Lepoutre C, Steichen O \& Guideline Working Group. European Society of Endocrinology Clinical Practice Guideline for long-term follow-up of patients operated on for a phaeochromocytoma or a paraganglioma. European Journal of Endocrinology 2016174 G1-G10. (https://doi.org/10.1530/EJE-160033)

4 Lenders JW, Duh QY, Eisenhofer G, Gimenez-Roqueplo AP, Grebe SK, Murad MH, Naruse M, Pacak K, Young Jr WF \& Endocrine Society. Pheochromocytoma and paraganglioma: an endocrine society clinical practice guideline. Journal of Clinical Endocrinology and Metabolism 201499 1915-1942. (https://doi.org/10.1210/jc.20141498)

5 Wong MY, Andrews KA, Challis BG, Park SM, Acerini CL, Maher ER \& Casey RT. Clinical Practice Guidance: Surveillance for phaeochromocytoma and paraganglioma in paediatric succinate dehydrogenase gene mutation carriers. Clinical Endocrinology 201990 499-505. (https://doi.org/10.1111/cen.13926)

6 Nicolas M \& Dahia P. Predictors of outcome in phaeochromocytomas and paragangliomas. F1000Research 201762160.

7 Benn DE, Gimenez-Roqueplo AP, Reilly JR, Bertherat J, Burgess J, Byth K, Croxson M, Dahia PL, Elston M, Gimm O, et al. Clinical presentation and penetrance of pheochromocytoma/paraganglioma syndromes. Journal of Clinical Endocrinology and Metabolism 200691 827-836. (https://doi.org/10.1210/jc.2005-1862)

8 Pacak K \& Tella SH. Pheochromocytoma and paraganglioma. In Endotext. Eds LJ De Groot, G Chrousos, K Dungan, KR Feingold, A Grossman, JM Hershman, C Koch, M Korbonits, R McLachlan, M New, et al. South Dartmouth, MA, USA: MDText.com, 2000. (available at: https://www.ncbi.nlm.nih.gov/books/NBK481899/)

9 Bardella C, Pollard PJ \& Tomlinson I. SDH mutations in cancer. Biochimica et Biophysica Acta 20111807 1432-1443. (https://doi. org/10.1016/j.bbabio.2011.07.003)

10 Gill AJ. Succinate dehydrogenase (SDH)-deficient neoplasia. Histopathology 201872 106-116. (https://doi.org/10.1111/his.13277)

11 Bennedbaek M, Rossing M, Rasmussen AK, Gerdes AM, Skytte AB, Jensen UB, Nielsen FC \& Hansen TVO. Identification of eight novel SDHB, SDHC, SDHD germline variants in Danish pheochromocytoma/paraganglioma patients. Heredity Cancer in Clinical Practice 20161413.

12 Bjorklund P, Pacak K \& Crona J. Precision medicine in pheochromocytoma and paraganglioma: current and future concepts. Journal of Internal Medicine 2016280 559-573. (https://doi. org/10.1111/joim.12507)

13 Oudijk L, Gaal J \& de Krijger RR. The role of immunohistochemistry and molecular analysis of succinate dehydrogenase in the diagnosis of endocrine and non-endocrine tumors and related syndromes.
Endocrine Pathology 201930 64-73. (https://doi.org/10.1007/s12022018-9555-2)

14 Thompson LD. Pheochromocytoma of the adrenal gland scaled score (PASS) to separate benign from malignant neoplasms: a clinicopathologic and immunophenotypic study of 100 cases. American Journal of Surgical Pathology 200226 551-566. (https://doi. org/10.1097/00000478-200205000-00002)

$15 \mathrm{Wu}$ D, Tischler AS, Lloyd RV, DeLellis RA, de Krijger R, van Nederveen F \& Nose V. Observer variation in the application of the pheochromocytoma of the adrenal gland scaled score. American Journal of Surgical Pathology 200933 599-608. (https://doi. org/10.1097/PAS.0b013e318190d12e)

16 Angelousi A, Kassi E, Zografos G \& Kaltsas G. Metastatic pheochromocytoma and paraganglioma. European Journal of Clinical Investigation 201545 986-997. (https://doi.org/10.1111/eci.12495)

17 Stenman A, Zedenius J \& Juhlin CC. The value of histological algorithms to predict the malignancy potential of pheochromocytomas and abdominal paragangliomas-a meta-analysis and systematic review of the literature. Cancers 201911 225. (https:// doi.org/10.3390/cancers11020225)

18 Lee H, Jeong S, Yu Y, Kang J, Sun H, Rhee JK \& Kim YH. Risk of metastatic pheochromocytoma and paraganglioma in SDHx mutation carriers: a systematic review and updated metaanalysis. Journal of Medical Genetics 202057 217-225. (https://doi. org/10.1136/jmedgenet-2019-106324)

19 Richards S, Aziz N, Bale S, Bick D, Das S, Gastier-Foster J, Grody WW, Hegde M, Lyon E, Spector E, et al. Standards and guidelines for the interpretation of sequence variants: a joint consensus recommendation of the American College of Medical Genetics and Genomics and the Association for Molecular Pathology. Genetics in Medicine 201517 405-424. (https://doi.org/10.1038/gim.2015.30)

20 Gronborg S, Darin N, Miranda MJ, Damgaard B, Cayuela JA, Oldfors A, Kollberg G, Hansen TVO, Ravn K, Wibrand F, et al. Leukoencephalopathy due to complex II deficiency and bi-allelic SDHB mutations: further cases and implications for genetic counselling. JIMD Reports 201733 69-77. (https://doi. org/10.1007/8904_2016_582)

21 Hamidi O, Young Jr WF, Iniguez-Ariza NM, Kittah NE, Gruber L, Bancos C, Tamhane S \& Bancos I. Malignant pheochromocytoma and paraganglioma: 272 patients over 55 years. Journal of Clinical Endocrinology and Metabolism 2017102 3296-3305. (https://doi. org/10.1210/jc.2017-00992)

22 Burnichon N, Briere JJ, Libe R, Vescovo L, Riviere J, Tissier F, Jouanno E, Jeunemaitre X, Benit P, Tzagoloff A, et al. SDHA is a tumor suppressor gene causing paraganglioma. Human Molecular Genetics 201019 3011-3020. (https://doi.org/10.1093/hmg/ddq206)

23 Elder EE, Xu D, Höög A, Enberg U, Hou M, Pisa P, Gruber A, Larsson C \& Bäckdahl M. Ki-67 AND hTERT expression can aid in the distinction between malignant and benign pheochromocytoma and paraganglioma. Modern Pathology 200316 246-255. (https://doi. org/10.1097/01.MP.0000056982.07160.E3)

24 Timmers HJ, Kozupa A, Eisenhofer G, Raygada M, Adams KT, Solis D, Lenders JW \& Pacak K. Clinical presentations, biochemical phenotypes, and genotype-phenotype correlations in patients with succinate dehydrogenase subunit B-associated pheochromocytomas and paragangliomas. Journal of Clinical Endocrinology and Metabolism 200792 779-786. (https://doi.org/10.1210/jc.2006-2315)

25 Bayley JP, Bausch B, Rijken JA, van Hulsteijn LT, Jansen JC, Ascher D, Pires DEV, Hes FJ, Hensen EF, Corssmit EPM, et al. Variant type is associated with disease characteristics in SDHB, SDHC and SDHD-linked phaeochromocytoma-paraganglioma. Journal of Medical Genetics 202057 96-103. (https://doi.org/10.1136/ jmedgenet-2019-106214)

26 Ricketts CJ, Shuch B, Vocke CD, Metwalli AR, Bratslavsky G, Middelton L, Yang Y, Wei MH, Pautler SE, Peterson J, et al. Succinate https://ec.bioscientifica.com https://doi.org/10.1530/EC- (c) 2020 The authors Published by Bioscientifica Ltd

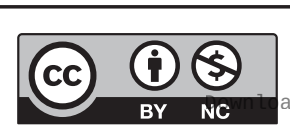

This work is licensed under a Creative Commons Attribution-NonCommercial 4.0 International License. ded from Bioscientifica.com at 04/26/2023 10:19:28AM 
dehydrogenase kidney cancer: an aggressive example of the Warburg effect in cancer. Journal of Urology 2012188 2063-2071. (https://doi. org/10.1016/j.juro.2012.08.030)

27 Schmidt M, Schmidt SA, Sandegaard JL, Ehrenstein V, Pedersen L $\&$ Sorensen HT. The Danish National Patient Registry: a review of content, data quality, and research potential. Clinical Epidemiology 20157 449-490. (https://doi.org/10.2147/CLEP.S91125)

28 Mathiesen JS, Kroustrup JP, Vestergaard P, Stochholm K, Poulsen PL, Rasmussen ÅK, Feldt-Rasmussen U, Gaustadnes M, Orntoft TF, Rossing M, et al. Founder effect of the RET(C611Y) mutation in multiple endocrine neoplasia 2A in Denmark: a nationwide study. Thyroid 201727 1505-1510. (https://doi.org/10.1089/ thy.2017.0404)
29 Persu A, Lannoy N, Maiter D, Mendola A, Montigny P, Oriot P, Vinck W, Garin P, Hamoir M \& Vikkula M. Prevalence and spectrum of SDHx mutations in pheochromocytoma and paraganglioma in patients from Belgium: an update. Hormone and Metabolic Research 201244 349-353. (https://doi.org/10.1055/s-0032-1311610)

30 Dansk Endokrinologisk Selskab. NBV: Fæokromocytom og paragangliom, 2018. Aalborg, Denmark: Dansk Endokrinologisk Selskab, 2018. (available at: http://www.endocrinology.dk/index.php/4hypofyse-og-binyresygdomme/3-faeokromocytom-og-paragangliom)

31 Ocal I, Avci A, Cakalagaoglu F \& Can H. Lack of correlations among histopathological parameters, Ki-67 proliferation index and prognosis in pheochromocytoma patients. Asian Pacific Journal of Cancer Prevention 201415 1751-1755. (https://doi.org/10.7314/apjcp.2014.15.4.1751)

Received in final form 29 June 2020

Accepted 19 July 2020

Accepted Manuscript published online 20 July 2020
This work is licensed under a Creative Commons Attribution-NonCommercial 4.0 International License. ded from Bioscientifica.com at 04/26/2023 10:19:28AM via free access 